Article

\title{
The Influence of Mycorrhizal Fungi on the Accumulation of Sennosides A and B in Senna alexandrina and Senna italica
}

\author{
Mashail N. AlZain ${ }^{1}$, Abdulrahman A. AlAtar ${ }^{2}$, Abdulaziz A. Alqarawi ${ }^{3}$, Ramzi A. Mothana ${ }^{4} \mathbb{D}$, \\ Omar M. Noman ${ }^{4}{ }^{(}$, Rashed N. Herqash ${ }^{4}$, Ebtesam S. AlSheddi ${ }^{4}\left(\mathbb{D}\right.$, Nida N. Farshori $^{4}$ and \\ Perwez Alam ${ }^{4, *}$ \\ 1 Department of Biology, College of Sciences, Princess Nourah bint Abdulrahman University, \\ Riyadh 11451, Saudi Arabia; mnalzain@pnu.edu.sa \\ 2 Department of Botany and Microbiology, College of Sciences, King Saud University, \\ Riyadh 11451, Saudi Arabia; aalatar@ksu.edu.sa \\ 3 Department of Plant Production, College of Food and Agricultural Sciences, King Saud University, \\ Riyadh 11451, Saudi Arabia; alqarawi@ksu.edu.sa \\ 4 Department of Pharmacognosy, College of Pharmacy, King Saud University, Riyadh 11451, Saudi Arabia; \\ rmothana@ksu.edu.sa (R.A.M.); onoman@ksu.edu.sa (O.M.N.); rhergash@ksu.edu.sa (R.N.H.); \\ ealsheddi@ksu.edu.sa (E.S.A.); nidachem@gmail.com (N.N.F.) \\ * Correspondence: aperwez@ksu.edu.sa; Tel.: +966-551362901 or +966-46-77191
}

Received: 29 October 2020; Accepted: 22 November 2020; Published: 25 November 2020

\begin{abstract}
Symbiotic arbuscular mycorrhizal fungi (AMF) play a major role in plant development, growth, and relationships with the environment through a change in the accumulation of secondary metabolites; hence, we planned to investigate AMF's influence on sennoside A and B accumulation in Senna alexandrina (SA) and Senna italica (SI). Seeds of SA (S. alexandrina free of mycorrhizae) and SI (S. italica free of mycorrhizae) were planted in two types of soils: +mycorrhiza and-mycorrhiza. The plant leaves of SA, SI, S. alexandrina with mycorrhizae (SAM) and S. italica with mycorrhizae (SIM) were collected and extracted (with $85 \%$ methanol), and sennoside A and B content was evaluated by the HPLC-UV method. The antioxidant activity of SA, SI, SAM and SIM was evaluated by using 2, 2-diphenyl-1-picrylhydrazyl (DPPH) and 2,2'-azino-bis (3-ethylbenzothiazoline-6-sulfonic acid) (ABTS) methods, while antimicrobial properties were evaluated by the minimum inhibitory concentration method (MIC). The AMF colonization was $85.66 \%$ and $85 \%$, respectively, in the roots of SA and SI. The HPLC analysis showed a significant increase in (\%) the content of sennoside A/sennoside B by 71.11/88.21, respectively, in SAM and 6.76/36.37 in SIM, which clearly indicated positive AMF effects. The DPPH/ABTS [The half maximal inhibitory concentration $\left(\mathrm{IC}_{50}\right): 235.9 / 321.5 \mu \mathrm{g} / \mathrm{mL}$ ] scavenging activity of SAM was comparatively higher and it also exhibited strong antibacterial action (MIC: $156.25 \mu \mathrm{g} / \mathrm{mL}$ ), which supported the increase in sennoside content. This finding may be useful for further investigations of the symbiotic relation of mycorrhizal fungi with other plant species.
\end{abstract}

Keywords: Senna; Leguminosae; mycorrhizae; sennosides; HPLC-UV; antimicrobial; antioxidant

\section{Introduction}

Leguminosae is one of the most widespread plant families in the world, containing the genus Senna, which includes hundreds of plant species [1]. Senna alexandrina and Senna italica contain safe medical compounds (sennoside A and sennoside B) that are used to treat many diseases, especially constipation problems [2,3]. The presence of sennoside A and sennoside B (anthraquinone derivatives) in both Senna leaves and fruit, increases bowel movements and reduces water absorption, which imparts their 
anticonstipation properties in humans [4]. The quantity of secondary metabolites varies depending on the type of plant, the part used, and environmental factors $[5,6]$. Soil organisms play a crucial role in the functioning of agricultural ecosystems. Mycorrhizal fungi are one of the most important soil microorganisms and major components of a sustainable soil-plant system. It is in the second-largest components of the soil [7] where these fungi establish a symbiotic relationship with more than $80 \%$ of plant species [8]. The association of mycorrhizal fungi with plant roots has mutual benefits for both the plant host and the fungus [9,10]. This relationship has a positive impact on most plants, both in terms of their morphological growth and the content of the secondary metabolites [11,12]. Mycorrhizae facilitates the interaction of the plant with its environment by mitigating the negative effects of stress factors [13]. Moreover, the exposure of plants to environmental and biotic stress enhances the accumulation of toxic ROS such as the superoxide radical $\left(\mathrm{O}_{2}{ }^{-}\right)$, hydrogen peroxide $\left(\mathrm{H}_{2} \mathrm{O}_{2}\right)$, hydroxyl radical $\left(\mathrm{OH}^{-}\right)$, and singlet oxygen $\left({ }^{1} \mathrm{O}_{2}\right)[14,15]$. ROS can severely disrupt the normal metabolism and cellular functions of plants through their oxidative damage to lipids, nucleic acids, oxidizing proteins, and photosynthetic pigments [15]. The induction of ROS-scavenging enzymes, such as superoxide dismutase (SOD), catalase (CAT), peroxidase (POD), ascorbate peroxidase (APX), and glutathione reductase (GR), is the most common mechanism used to scavenge toxic ROS during salt stress [16,17]. Several studies have demonstrated that AM symbiosis can serve to protect the host plants against oxidative damage during salt stress. The higher antioxidant enzyme activity in mycorrhizal plants helps to rapidly and efficiently remove excess ROS [18-22]. The information detailed in previously mentioned investigations justifies the conventional utilization of mycorrhizal fungi to increase the secondary metabolite production for medicinal purposes.

Based on these data, our work aimed to investigate the change in the content of sennoside A and sennoside B in Senna alexandrina and Senna italica in both soil free of mycorrhizal fungi and soil containing mycorrhizae using a High-Performance Liquid Chromatography (HPLC) method. Evaluation of the antioxidant activity of -mycorrhizae Senna (SA and SI) and +mycorrhizae Senna (SAM and SIM, respectively) was done by using 2,2-diphenyl-1-picrylhydrazyl (DPPH) and 2,2'-azino-bis (3-ethylbenzothiazoline-6-sulfonic acid) (ABTS) methods. The antimicrobial activity of all extracts was also evaluated using the minimum inhibitory concentration method (MIC).

\section{Materials and Methods}

\subsection{Chemicals and Reagents}

Methanol and acetonitrile of HPLC grade were obtained from Fisher Scientific UK. A Millipore Milli-Q ${ }^{\circledR}$ (Bedford, MA, USA) assembly was used to obtain highly pure water. A Millipore-Millex-HV ${ }^{\circledR}$ filter unit with a membrane filter $(0.45 \mu \mathrm{m}$ pore size) was used for the filtration of solvents, and a syringe filter of $0.22 \mu \mathrm{m}$ was used for sample preparation. The two natural compound biomarkers, sennoside A (Figure 1A) and sennoside B (Figure 1B), were purchased from PhytoLab (Dutendorfer Str. 5, 91487 Vestenbergsgreuth, Germany).

\subsection{Collection of the Plant Materials}

The seeds of S. alexandrina and S. italica were collected from a plant growth area in the Al-Baha region of Western Saudi Arabia in 2018. They were identified by Prof. Abdulaziz A. ALQarawi and deposited in the herbarium of the Faculty of Science, King Saud University.

\subsection{Identification and Quantification of Mycorrhizal Spores from Soil Samples}

A soil sample $(100 \mathrm{~g})$ was taken from the Al-Baha plant growth region and then mixed with $150 \mathrm{~mL}$ of distilled water in a conical flask in the lab. The conical flask was then shaken for $45 \mathrm{~min}$ and kept in an undisturbed condition for $30 \mathrm{~min}$. Mycorrhizal spores were obtained by wet sieving and decanting [23]. The solution was passed through 500, 250, 106, and $45 \mu \mathrm{m}$ sieves with a slow stream of water was added and repeated three times. The large spores were collected from the residue present 
on the sieves. These spores were transferred to the centrifugation tubes and centrifuged for $2 \mathrm{~min}$ at a speed of $3000 \mathrm{rpm}$. The spores present in the filter paper were taken and identified based on the color and size of the spores as well as the number and shape of the walls using INVAM, 2013 [24].

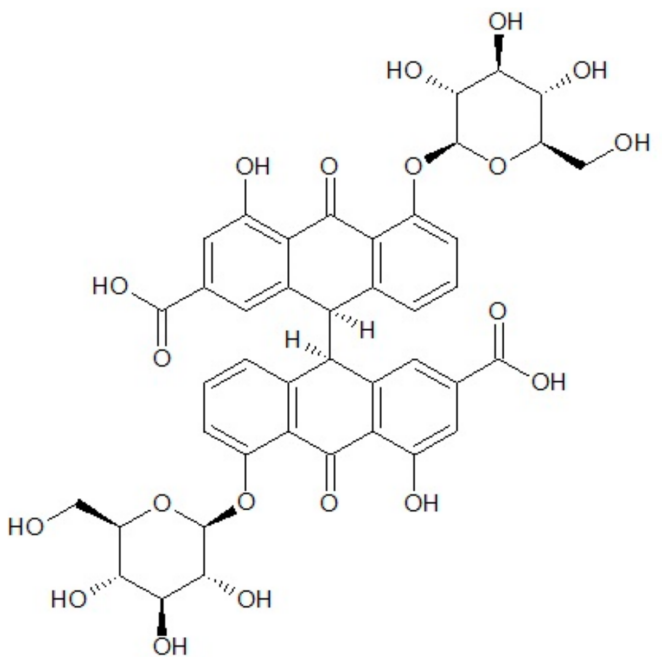

(A)<smiles></smiles>

(B)

Figure 1. Chemical structure of biomarkers sennoside A (A) and sennoside B (B).

\subsection{Planting Method}

The seeds of S. alexandrina and S. italica were planted inside the growth chamber of the College of Food and Agricultural Sciences at King Saud University for 5 months using two types of soil and 10 repeats for each. The first soil type contained mycorrhizae collected from the Al-Baha region, while the other soil was sterilized by autoclaving at a temperature of $120^{\circ} \mathrm{C}$ for $1 \mathrm{~h}$ three consecutive times to get rid of the mycorrhiza spread inside the soil. Soil extracts that contained microorganisms were then passed through a $25-\mu \mathrm{m}$ sieve (to remove spores of mycorrhizal fungi and allow other microorganisms to pass) and placed in sterile agricultural pots. The seeds were then cleaned with a $0.5 \%$ sodium hypochlorite $(\mathrm{NaOCl})$ solution for $3 \mathrm{~min}$ and washed three times with sterile distilled water. The plants were interchangeably exposed to $12 \mathrm{~h}$ of lighting $\left(25^{\circ} \mathrm{C}\right)$ and $12 \mathrm{~h}$ of darkness $\left(35^{\circ} \mathrm{C}\right)$, respectively, at $70 \%$ humidity. Irrigation was performed as needed with the addition of $10 \%$ of Hoagland's nutrient-free phosphorus solution per week. After 5 months of planting, the harvesting process was carried out carefully and by hand, taking care not to shatter the root hairs. The leaves were then dried and stored in dark glass cans at room temperature until extraction. Root samples grown in soil containing mycorrhizal fungi were washed with a slow stream of water and stored in formalin acetic acid solution (FAA) in special tubes, dyed and examined for relative mycorrhizal dependency (RDM).

$$
\begin{gathered}
\mathrm{RDM}=[(\text { Treatment with mycorrhizal plant }- \text { Treatment nonmycorrhizal } \\
\text { plant }) / \text { Treatment with mycorrhizal plant }] \times 100 .
\end{gathered}
$$

\subsection{Estimation of Mycorrhizal Root Colonization}

The mycorrhizal root colonization of S. alexandrina and S. italica was determined according to the method described by Philiips and Hayman [25] with modifications. The root pieces after harvest were thoroughly washed in water and boiled with $7 \%$ potassium hydroxide $(\mathrm{KOH})$ at $90^{\circ} \mathrm{C}$ for $1 \mathrm{~h}$. The segments were washed in distilled water, acidified with $1(\mathrm{~N}) \mathrm{HCl}(\mathrm{pH}=2.2)$, and stained with $0.05 \%$ trypan blue. The root segments were placed temporarily in a preservative containing glycerol 
( $500 \mathrm{~mL}$ of glycerol, $450 \mathrm{~mL}$ of water, and $50 \mathrm{~mL}$ of $1 \% \mathrm{HCl}$ ). The mycorrhizal percentage was calculated within the infected regions of the roots according to the following formula:

$\%$ Mycorrhizal association $=($ Total number of mycorrhizae associated segments/Total number of segments scored) $\times 100$.

\subsection{Sample Processing and Extraction}

The leaves of the plants $(5.0 \mathrm{~g})$ were collected immediately after harvest, dried in the shade for 10 days, and then roughly ground. Samples were extracted with $85 \%$ methanol in a Soxhlet apparatus for $36 \mathrm{~h}$. The crude extracts of SA (S. alexandrina free of mycorrhizae), SI (S. italica free of mycorrhizae), SAM (S. alexandrina with mycorrhizae), and SIM (S. italica with mycorrhizae) were then concentrated under reduced pressure. The dry extracts were kept for further experimental processes.

\subsection{Analysis of sennosides A and B in SA, SAM, SI and SIM Extracts by HPLC-UV Method}

For quantification, an Alliance 2695 Separations Module equipped with a 2487 dual-wavelength absorbance detector (Waters Instruments, Inc., Milford, MA) was used. Chromatographic analysis was carried out with the following equipment: a built-in quaternary pump, Pinnacle C18 column (5 $\mu \mathrm{m}$, $250 \times 4.6 \mathrm{~mm}$ ), four-channel degasser, and an auto sampler with a programmable temperature $\left(25^{\circ} \mathrm{C}\right)$. The mobile phase was composed of different proportions of $0.5 \%$ formic acid in ultra-pure water (A) and acetonitrile $(B)$ and the flow rate was $1 \mathrm{~mL} / \mathrm{min}$. The optimized gradient program was as follows: 0-15 min (15-30\% B), 15-18 min (30-34\% B), 18-20 min (34-40\% B), 20-21 min (40-15\% B), 21-25 min (15\% B). Samples $(1 \mathrm{mg} / \mathrm{mL}$, each) were injected into the system as $10 \mu \mathrm{L}$. The output signal $(272 \mathrm{~nm})$ was detected and processed using EMPOWER software version 2.

\subsection{Antioxidant Activity}

\subsubsection{DPPH Radical-Scavenging Assay}

The antioxidative activity of SA, SAM, SI, and SIM was estimated by utilizing 2, 2-diphenyl1-picrylhydrazyl (DPPH), as reported earlier by Alqahtani et al. (2019) [26]. This test evaluates the free radical scavenging capacity of the samples being investigated. Various concentrations of the extracts $(10,50,100,500$, and $1000 \mu \mathrm{g} / \mathrm{mL})$ were prepared. Afterwards, $500 \mu \mathrm{L}$ of each concentration was added to $125 \mu \mathrm{L}$ of DPPH and $375 \mu \mathrm{L}$ of methanol and incubated for $30 \mathrm{~min}$ at room temperature. The antioxidant activity was measured in absorbance mode at $\lambda \max =517 \mathrm{~nm}$ spectrophotometrically (UV mini-1240, Shimadzu, Japan). Ascorbic acid was used as a positive control. The radical scavenging activity was then calculated based on the following equation:

$$
\% \text { of radical scavenging activity }=(\text { Abs control }- \text { Abs sample } / \text { Abs control }) \times 100
$$

\subsubsection{ABTS Radical Cation Scavenging Activity}

The antioxidative activity of the extracts (SA, SAM, SI, and SIM) was assessed by applying the 2,2'-azino-bis (3-ethylbenzothiazoline-6-sulfonic acid) (ABTS) method as reported by Li et al. (2009) [27]. Aqueous solutions of ABTS $(7 \mathrm{mmol} / \mathrm{L})$ and potassium persulfate $(2.45 \mathrm{mmol} / \mathrm{L})$ were prepared. After $12 \mathrm{~h}$ in the dark, the two solutions were mixed and incubated for $30 \mathrm{~min}$, kept in a refrigerator for $24 \mathrm{~h}$, and then diluted in ethanol. Different prepared concentrations of each extract $(10,50,100,500$, and $1000 \mu \mathrm{g} / \mathrm{mL})$ were pipetted into ABTS solutions of $50 \mu \mathrm{g} / \mathrm{mL}$ (1:1) to initiate the reaction for a calibration curve. The absorbance was read at a wavelength of $\lambda=734 \mathrm{~nm}$. Ethanol (95\%) was used as a blank. ABTS $(50 \mu \mathrm{g} / \mathrm{mL})$ solution was used as the control. Ascorbic acid was used as the 
standard. Three replicates for the standard and each extract were used for analysis. The percentage of antioxidant capacity for each extract was calculated using the following formula [28].

$$
\% \text { of radical scavenging activity }=(\text { Abs control }- \text { Abs sample } / \text { Abs control }) \times 100
$$

\subsection{Antimicrobial Activity}

\subsubsection{Test Microorganisms}

The antimicrobial activity test was carried out on two Gram-positive bacteria, Staphylococcus aureus [The American Type Culture Collection (ATCC) 25923] and Enterococcus faecalis (ATCC 29212), two Gram-negative bacteria, Escherichia coli (ATCC 25922) and Proteus vulgaris (ATCC 8427), and one fungal strain, Candida albicans (ATCC 60193).

\subsubsection{Minimum Inhibitory Concentrations}

The minimum inhibitory concentration method (MIC) was utilized for the determination of the antimicrobial activity of the extracts SA, SAM, SI, and SIM (at 2000 to $31.2 \mu \mathrm{g} / \mathrm{mL}$ concentrations for each sample) using the previously used method described by Mann et al. [29,30], with some modifications. Two-fold serial dilutions of each plant sample $(100 \mu \mathrm{L} /$ well $)$ were made in the required broth media to achieve 2000 to $31.2 \mu \mathrm{g} / \mathrm{mL}$ concentrations, and were plated on sterile 96 -well plates. Thereafter, $100 \mu \mathrm{L}$ of each bacterial or fungal suspension was then added. The plate containing bacterial strains and plant samples was incubated at $37^{\circ} \mathrm{C}$ for $24 \mathrm{~h}$. The other plate, containing fungal strains + plant samples, was incubated at $25^{\circ} \mathrm{C}$ for $72 \mathrm{~h}$. MIC is the lowest concentration displaying no detectable bacterial or fungal growth. Gentamycin and nystatin were used as positive controls. The minimum bactericidal concentration (MBC) and the minimum fungicidal concentration (MFC) were also estimated. For MBC and MFC estimation, $5 \mu \mathrm{L}$ were taken from the wells that showed no growth, transferred to agar plates, and further incubated for $24 \mathrm{~h}$. MBC and MFC are the lowest concentrations that evidenced no visible bacterial or fungal growth.

\subsection{Statistical Analysis}

ANOVA and Origin Pro 8.5 were used for statistical analysis. Antioxidant experiments were performed in triplicate; the other experiments were performed using 10 replicates each. A data comparison of averages by differences in means was determined by the least significant difference (LSD) $(p=0.05)$ test. The type of correlation and the relationship between variables based on the value of $r$ were studied using statistical analysis software (SAS).

\section{Results}

\subsection{Determination of the Density, Types of Spores, and Mycorrhiza Colonization}

The spores were estimated at 310 spores per $20 \mathrm{~g}$. Ten types of spores were found: Septoglomus constrictum, Claroideoglomus etunicatum, Funneliformis geosporus, Glomus ambisporum, Gigaspora albida, Gigaspora margarita, Funneliformis coronatum, Gigaspora gigantea, Rhizophagus intraradices, and Rhizophagus fasciculatus. The rate of colonization within the root hairs of the vegetation of S. alexandrina and S. italica was 85.6 and $85 \%$, respectively. This ratio indicated the strength of the relationship between mycorrhizae and plants, and the dependence of each was determined by the growth of both plants after 5 months of cultivation in growth chambers with continuous monitoring (Figure 2A). It was clear that this relationship has a positive impact on the morphological growth of the two plants (Figure 2B). 
(A)

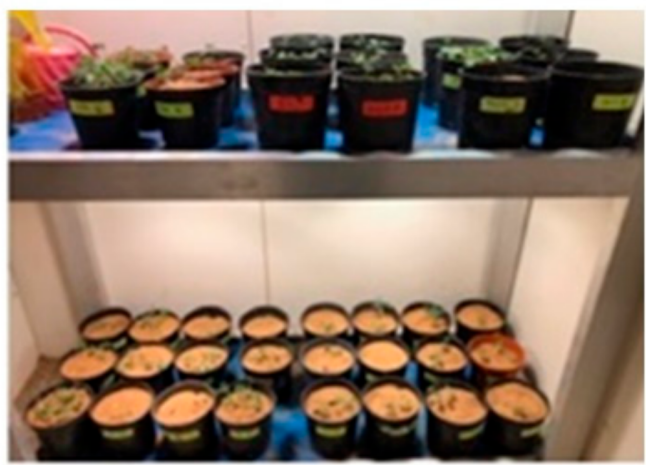

(B)

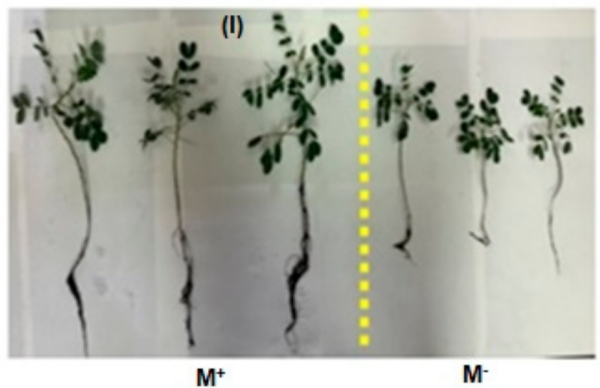

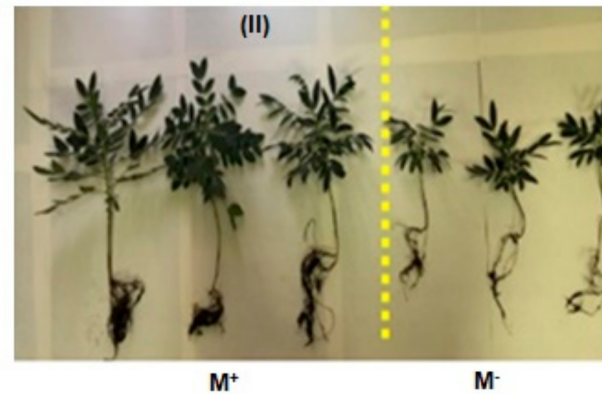

Figure 2. (A) Cultivation of S. alexandrina and S. italica plants in the growth chambers of the College of Food and Agricultural Sciences at King Saud University. (B) The changes in the characteristics of growth of S. italica (I) and S. alexandrina (II) in the presence and absence of mycorrhizal fungi.

\subsection{Analysis of sennosides A and B in SA, SAM, SI, and SIM by HPLC-UV Method}

The developed HPLC method was found to furnish a sharp and intense peak of sennoside A and sennoside $\mathrm{B}$ at $\mathrm{Rt}=6.937$ and 9.634, respectively (Figure $3 \mathrm{~A}$ ), with a high baseline resolution using acetonitrile and $0.5 \%$ formic acid in ultra-pure water as a suitable mobile phase (in a gradient system) at a flow rate of $1 \mathrm{~mL} / \mathrm{min}$, in the linearity range of $1-40 \mu \mathrm{g} / \mathrm{mL}$. The linear regression equation/coefficient of correlation $\left(\mathrm{r}^{2}\right)$ for sennoside A and sennoside B were found to be $Y=55402 x-42657 / 0.9918$ and $Y=66996 x-54283 / 0.9912$, respectively. The Limit of detection (LOD)/Limit of quantification (LOQ) for sennoside A and sennoside B were found to be $1.58 / 4.79 \mu \mathrm{g} / \mathrm{mL}$ and $1.63 / 4.95 \mu \mathrm{g} / \mathrm{mL}$, respectively. The developed HPLC method was found to be precise as percentage relative standard deviation (\%RSD) values for repeatability of intra-day/inter-day precision studies of sennoside A and sennoside B were 0.05-0.45/0.78-0.98 and 0.07-1.61/0.61-1.04, respectively, which is below the limit of $2.0 \%$ (as suggested by the International Conference on Harmonization guidelines). The developed HPLC method furnished the good separation of different phytoconstituents present in SA (Figure 3B), SAM (Figure 3C), SI (Figure 3D) and SIM (Figure 3E). The quantity ( $\mu \mathrm{g} / \mathrm{mg}$, of dried weight of extract) of sennosides A and B in SA extract was found to be 2.25 and $10.78 \mu \mathrm{g} / \mathrm{mg}$, respectively, and it was found to be increased in the SAM extract at 3.85 and $20.29 \mu \mathrm{g} / \mathrm{mg}$, respectively. Moreover, the quantity of sennosides A and B in SI was 4.73 and $13.69 \mu \mathrm{g} / \mathrm{mg}$, while in SIM it was 5.05 and $18.67 \mu \mathrm{g} / \mathrm{mg}$, respectively (Table 1), which indicated that there is less mycorrhizal influence on $S$. italica in comparison to S. alexandrina with respect to the increase in sennoside A and B content. 

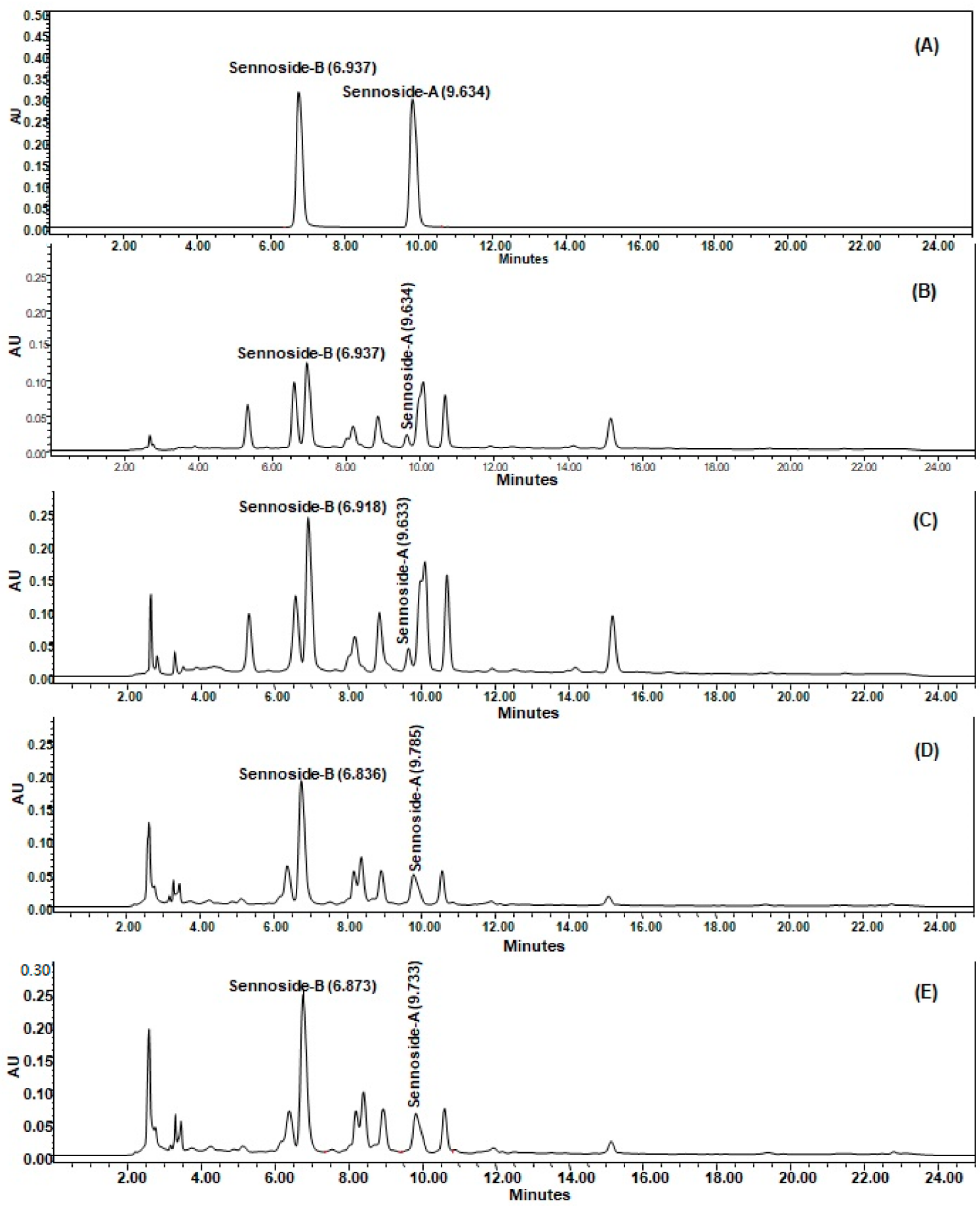

Figure 3. Sennoside A and sennoside B estimation in Senna alexandrina (SA), S. alexandrina with mycorrhizae (SAM), Senna italica (SI) and and S. italica with mycorrhizae (SIM) by HPLC-UV method (conditions: Pinnacle C18 column $(4.6 \times 250 \mathrm{~mm}, 5 \mu \mathrm{m})$; mobile phase, acetonitrile: $0.5 \%$ formic acid in ultra-pure water (gradient system); flow rate, $1 \mathrm{~mL} / \mathrm{min}$; UV detection at $\lambda \mathrm{max}=272 \mathrm{~nm}$ at temperature $\left(25 \pm 1^{\circ} \mathrm{C}\right)$. (A) Representative chromatogram of sennoside B $(\mathrm{Rt}=6.937)$ and sennoside A $(\mathrm{Rt}=9.634)$; $(\mathrm{B})$ The retention times $(\mathrm{Rt})$ of sennoside B and sennoside A from SA were 6.937 and 9.634 min, respectively; (C) from SAM, they were 6.918 and $9.633 \mathrm{~min}$, respectively; (D) from SI, they were 6.836 and $9.785 \mathrm{~min}$, respectively; (E) from SIM, they were 6.873 and $9.733 \mathrm{~min}$, respectively. 
Table 1. HPLC-UV analysis of sennoside A and sennoside B in SA, SAM, SI, and SIM.

\begin{tabular}{cccc}
\hline S. No. & Sample & $\begin{array}{c}\text { Sennoside A Content }(\mu \mathrm{g} / \mathrm{mg} \text { of Dried } \\
\text { Weight of Extract) }\end{array}$ & $\begin{array}{c}\text { Sennoside B Content }(\mu \mathrm{g} / \mathrm{mg} \text { of Dried } \\
\text { Weight of Extract) }\end{array}$ \\
\hline 1. & SA & $2.25 \pm 0.07$ & $10.78 \pm 0.89$ \\
\hline 2. & SAM & $3.85 \pm 0.19$ & $20.29 \pm 1.17$ \\
\hline 3. & SI & $4.73 \pm 0.09$ & $13.69 \pm 0.23$ \\
\hline 4. & SIM & $5.05 \pm 0.23$ & $18.67 \pm 0.32$ \\
\hline
\end{tabular}

\subsection{Antioxidant Activity}

The results of the radical scavenging and antioxidative activities are shown in Table 2 (Figure 4). In the DPPH method, SAM and SIM showed strong DPPH scavenging activity ( $\mathrm{IC}_{50} 235.9 \mu \mathrm{g} / \mathrm{mL}$ and $946 \mu \mathrm{g} / \mathrm{mL}$, respectively). The DPPH scavenging activity $\mathrm{IC}_{50}$ for SA was $436.8 \mu \mathrm{g} / \mathrm{mL}$ and was $\geq 1 \mathrm{mg} / \mathrm{mL}$ for SI. Moreover, SAM also showed strong ABTS scavenging activity $\left(\mathrm{IC}_{50} 321.5 \mu \mathrm{g} / \mathrm{mL}\right)$, while the ABTS $\mathrm{IC}_{50}$ of SA was $501.6 \mu \mathrm{g} / \mathrm{mL}$.

Table 2. DPPH and ABTS scavenging activities of SA, SAM, SI, and SIM.

\begin{tabular}{|c|c|c|c|c|c|}
\hline \multirow[t]{2}{*}{ Sample } & \multicolumn{5}{|c|}{ (DPPH-Radical Scavenging Activity in \%) } \\
\hline & $10(\mu \mathrm{g} / \mathrm{mL})$ & $50(\mu \mathrm{g} / \mathrm{mL})$ & $100(\mu \mathrm{g} / \mathrm{mL})$ & $500(\mu \mathrm{g} / \mathrm{mL})$ & $1000(\mu \mathrm{g} / \mathrm{mL})$ \\
\hline SA & $12.7 \pm 0.9$ & $20.3 \pm 1.3$ & $34.3 \pm 1.9$ & $53.3 \pm 2.1$ & $69.7 \pm 2.3$ \\
\hline SAM & $23.5 \pm 0.4$ & $32.3 \pm 0.3$ & $45.1 \pm 1.2$ & $60.3 \pm 0.2$ & $72.2 \pm 1.9$ \\
\hline SI & $2.3 \pm 0.3$ & $10.2 \pm 3.1$ & $19.7 \pm 0.7$ & $31.7 \pm 2.1$ & $44.7 \pm 1.3$ \\
\hline SIM & $7.3 \pm 2.8$ & $13.2 \pm 0.9$ & $27.1 \pm 2.2$ & $41.2 \pm 1.4$ & $51.6 \pm 2.3$ \\
\hline Ascorbic acid & $80.7 \pm 2.0$ & $85.1 \pm 1.3$ & $85 \pm 1.2$ & $88.7 \pm 2.4$ & $90.7 \pm 1.4$ \\
\hline \multicolumn{6}{|c|}{ (ABTS Radical Cation Scavenging Activity in \%) } \\
\hline SA & $10.2 \pm 0.7$ & $17.1 \pm 1.2$ & $30.3 \pm 1.1$ & $50.1 \pm 1.5$ & $65.1 \pm 1.2$ \\
\hline SAM & $19.5 \pm 0.6$ & $29.4 \pm 0.9$ & $42.1 \pm 2.2$ & $57.1 \pm 0.9$ & $69.8 \pm 1.5$ \\
\hline SI & $2.3 \pm 1.9$ & $8.2 \pm 2.1$ & $15.7 \pm 1.9$ & $29.8 \pm 2.1$ & $40.3 \pm 1.7$ \\
\hline SIM & $5.8 \pm 2.3$ & $10.2 \pm 1.9$ & $24.1 \pm 1.2$ & $37.9 \pm 1.6$ & $47.9 \pm 2.6$ \\
\hline Ascorbic acid & $80.7 \pm 2.4$ & $81.2 \pm 2.1$ & $84.2 \pm 1.9$ & $87.2 \pm 2.4$ & $88.7 \pm 2.1$ \\
\hline
\end{tabular}

In the columns, means \pm SD are significant at $p<0.05(n=3)$.

(A)

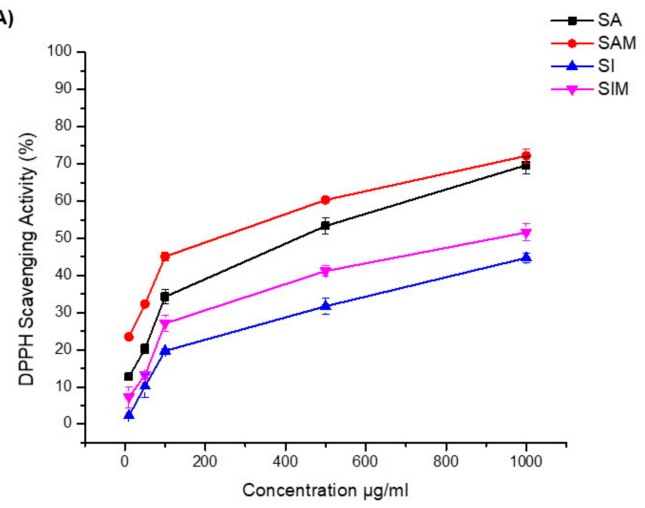

(B)

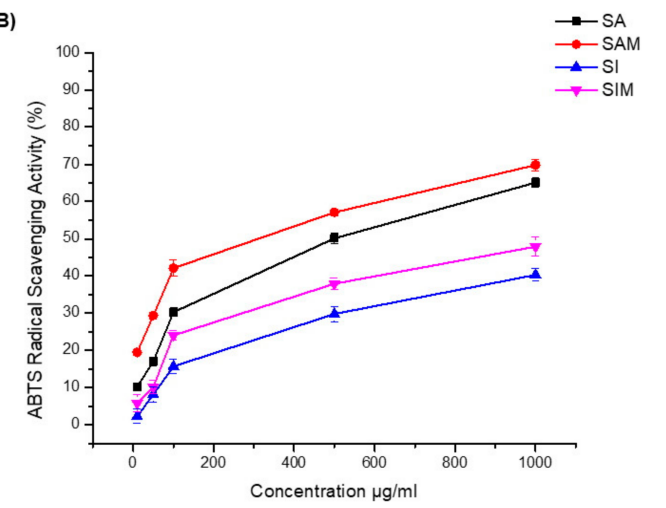

Figure 4. Antioxidant activities of SA, SI, SAM, and SIM. (A) 2-diphenyl-1-picrylhydrazyl (DPPH) scavenging activity of SA, SI, SAM, and SIM; (B) 2,2'-azino-bis (3-ethylbenzothiazoline-6-sulfonic acid) (ABTS) scavenging activity of SA, SI, SAM, and SIM. Data were analyzed using Origin Pro 8 software. 


\subsection{Antimicrobial Activity}

The four sample extracts demonstrated varying levels of antibacterial and antifungal activities, as shown in Table 3. SAM and SIM showed strong bacterial and fungal growth inhibition against Gram-positive bacteria (S. aureus and E. faecalis), with a MIC of $156.25 \mu \mathrm{g} / \mathrm{mL}$ when compared with SA and SI, respectively. Moreover, both plants (SAM and SIM) showed antibacterial activity against Gram-negative bacteria, with a MIC of $625 \mu \mathrm{g} / \mathrm{mL}$ against $E$. coli and $312.5 \mu \mathrm{g} / \mathrm{mL}$ against P. vulgaris, while SA and SI showed no effects against Gram-negative bacteria and weak activity against Gram-positive, with a MIC of $625 \mu \mathrm{g} / \mathrm{mL}$ against $S$. aureus and $312.5 \mu \mathrm{g} / \mathrm{mL}$ against E. faecali. All plant extracts showed variable activities against Candida albicans (ATCC 60193).

Table 3. Minimal inhibitory concentrations (MICs), minimal bactericidal concentrations (MBCs), and minimal fungicidal concentrations (MFCs) of SA, SAM, SI, and SIM.

\begin{tabular}{|c|c|c|c|c|c|c|}
\hline Test Extracts & Activity & $\begin{array}{l}\text { S. aureus } \\
\mu \mathrm{g} / \mathrm{mL})\end{array}$ & $\begin{array}{l}\text { E. faecalis } \\
(\mu \mathrm{g} / \mathrm{mL})\end{array}$ & $\begin{array}{c}\text { E. coli } \\
(\mu \mathrm{g} / \mathrm{mL})\end{array}$ & $\begin{array}{l}\text { P. vulgaris } \\
(\mu \mathrm{g} / \mathrm{mL})\end{array}$ & $\begin{array}{c}\text { Candida albicans } \\
(\mu \mathrm{g} / \mathrm{mL})\end{array}$ \\
\hline \multirow{3}{*}{ SA } & MIC & 625 & 312.5 & - & - & 156.25 \\
\hline & $\mathrm{MBC}$ & 1250 & 625 & - & - & NT \\
\hline & MFC & NT & NT & NT & NT & 312.5 \\
\hline \multirow{3}{*}{ SI } & MIC & 625 & 312.5 & - & - & 156.25 \\
\hline & $\mathrm{MBC}$ & 1250 & 625 & - & - & NT \\
\hline & MFC & NT & NT & NT & NT & 312.5 \\
\hline \multirow{3}{*}{ SAM } & MIC & 156.25 & 156.25 & 625 & 312.5 & 78.12 \\
\hline & $\mathrm{MBC}$ & 312.5 & 312.5 & 1250 & 625 & NT \\
\hline & MFC & NT & NT & NT & NT & 156.25 \\
\hline \multirow{3}{*}{ SIM } & MIC & 156.25 & 156.25 & 625 & 312.5 & 78.12 \\
\hline & MBC & 312.5 & 312.5 & 1250 & 625 & NT \\
\hline & MFC & NT & NT & NT & NT & 156.25 \\
\hline \multirow{2}{*}{ Gentamycin } & MIC & 7.8 & 7.8 & 3.9 & 3.9 & NT \\
\hline & $\mathrm{MBC}$ & 15.6 & 15.6 & 7.8 & 7.8 & NT \\
\hline \multirow{2}{*}{ Nystatin } & MIC & NT & NT & NT & NT & 3.5 \\
\hline & MFC & NT & NT & NT & NT & 7.0 \\
\hline
\end{tabular}

S. aureus (ATCC 25923) and E. faecalis (ATCC 29212), two Gram-negative bacteria, E. coli (ATCC 25922) and P. vulgaris (ATCC 8427), and one fungal strain, Candida albicans (ATCC 60193). NT: not tested, -: no activity.

\section{Discussion}

The results reveal the vitality of the spores and the dependence of both plants for the emergence of a symbiotic relationship and a mutually beneficial relationship with mycorrhizae. This relationship led to a significant change in the accumulation of important secondary metabolites used for medicinal purposes, as indicated by the increase in the accumulation of sennoside compounds in this report.

The change in the accumulation of these compounds explains the role of mycorrhizae in the activation of some enzymes, whose composition is related to the alteration of the biological pathway of some genes. Mandal et al. [31] explained that the accumulation of the artemisinin compound has changed as a result of the relationship of mycorrhizae and its role in activating some of the enzymes responsible for its artemisinin synthesis in Artemisia annua. Furthermore, Tejavathi et al. [32] showed that the increase occurred in andrographolide compounds (used in the treatment of immune diseases) produced from Andrographis paniculata when the plant was grown in a soil with mycorrhizal fungi. The relationship between mycorrhizal fungi and the increase in pterocarpans and furanocoumarin produced from Bituminari bituminosa L. was observed by Pistelli et al. [12]. The interaction of 
Ocimum basilicum with various Glomus (genus of arbuscular mycorrhizal fungi) species enhanced the rosmarinic acid and caffeic acid (antioxidant compounds) levels in the plant [33,34]. Zubek el al. [35] also observed that the concentrations of hypericin and pseudohypericin (anthraquinone derivative) were enhanced in Hypericum perforatum upon treatment with mycorrihza. It was also observed by Giovannetti et al. [36] that the lycopene level was increased by $18.5 \%$ in tomato fruits produced by myccorhizal plants in comparison to the control.

The effect of mycorrhizae can be directed to the enzyme responsible for the biosynthetic pathway of anthraquinone glycosides in the genus Senna. This is called isochorismate synthase (Ics), and plays a major role in changing metabolic pathways [37], so it is possible to use this biotechnology to improve the accumulation of important compounds used for medicinal purposes to treat many diseases. Many studies have also indicated that mycorrhizae play a significant role in increasing the accumulation of many antioxidants, phenols, and flavonoids for the same reason that mycorrhizae activate enzymes responsible for promoting the accumulation of these secondary metabolites $[38,39]$. This increase in the accumulation of these important compounds plays a positive role in the elimination of some pathogenic microbes [40]. It was observed that the antioxidant activity of the two plant species (SAM and SAM) was increased with the presence of mycorrhizae. These results are in agreement with the data reported by Chang et al. (2018) [14], showing that arbuscular mycorrhizal symbiosis modulates the antioxidant response of Elaeagnus angustifolia. Moreover, the antimicrobial activity was also increased when the plants were grown in a soil containing a high amount of mycorrhizal fungi. Our results are in agreement with the data reported by Chatterjeesup et al., showing that the presence of these mycorrhizae helped to increase the accumulation of these compounds and increased the ability of the Cassia alata extract to fight these organisms [41].

These studies are consistent with the results of the current research, which show the dependence of both plants on mycorrhizae in the synthesis of sennosides A and B (as shown in HPLC analysis), which is further supported by their antioxidant property. HPLC analysis of the anthraquinones in Senna was proceed on a reversed-phase (RP) column using organic solvents such as acetonitrile or methanol, and aqueous acetic acid or formic acid [42,43]. In this study, we aimed to develop a simple and rapid method to simultaneously separate and determine sennosides A and B in Senna extract. Since most of the compounds present in the extract are known to be polar compounds, methods were developed based on reversed-phase (RP-18) HPLC. Therefore, mixtures of acetonitrile: water in different proportions were tested in the mobile phase for HPLC analyses, as were the effects of adding formic acid to adjust the $\mathrm{pH}$ value $(\mathrm{pH} 4.1)$ and solvent strength over the separation. The best resolution was achieved using a gradient profile of water in $0.5 \%$ formic acid (solvent $\mathrm{A}$ ) and acetonitrile (solvent B), as described in the Experimental section. A significant improvement in the separation and resolution of the peaks was also observed after adding formic acid. UV spectra chromatography showed that the absorbance at a single wavelength of $272 \mathrm{~nm}$ is the most generally used method for the quantification of separated mixtures of sennosides A and B [44]; therefore, the UV-vis detector was set at $272 \mathrm{~nm}$.

\section{Conclusions}

In this experiment, we investigated the effect of mycorrhizal fungi present in soil on the accumulation of the secondary metabolites sennosides A and B in Senna alexandrina and Senna italica using the High-Performance Liquid Chromatographic (HPLC) method, and determined their antioxidant and antimicrobial potential. It is evident that the symbiotic relationship between both Senna species and mycorrhizal fungi leads to an increase in the accumulation of sennosides A and B, especially in S. alexandrina (accumulation of sennosides A and sennoside B increased by $71.11 \%$ and $88.21 \%$, respectively). The increase in the content of sennosides A and B also resulted in a significant increase in antioxidant and antimicrobial activities. This finding may be useful in further investigations into the impact of the symbiotic relationships between mycorrhizal fungi and other plant species with respect to the increase in the accumulation of important secondary metabolites. The developed HPLC 
method can also be useful in the determination of sennosides A and B in other Senna species, finished herbal products containing Senna, and in process quality control.

Author Contributions: Conceptualization, M.N.A.; methodology, N.N.F., A.A.A. (Abdulrahman A. AlAtar); validation, O.M.N., R.N.H.; investigation, M.N.A. and A.A.A. (Abdulaziz A. Alqarawi); writing-original draft preparation, E.S.A. and P.A.; formal analysis, R.A.M.; supervision, A.A.A. (Abdulaziz A. Alqarawi); funding acquisition, M.N.A. All authors have read and agreed to the published version of the manuscript.

Funding: This research was funded by the Deanship of Scientific Research at Princess Nourah bint Abdulrahman University through the Fast-track Research Funding Program.

Acknowledgments: The authors acknowledge the Fast-track Research Funding Program of Deanship of Scientific Research at Princess Nourah bint Abdulrahman University, KSA for its financial support.

Conflicts of Interest: The authors declare that there are no conflicts of interest.

\section{References}

1. Marazzi, B.; Endress, P.K.; Queiroz, L.P.; Conti, E. Phylogenetic relationships within Senna (Leguminosae, Cassiinae) based on three chloroplast DNA regions: Patterns in the evolution of floral symmetry and extrafloral nectaries. Am. J. Bot. 2006, 93, 288-303. [CrossRef]

2. Singh, S.; Singh, S.K.; Yadav, A. A review on Cassia species: Pharmacological, traditional and medicinal aspects in various countries. AJPCT 2013, 1, 291-312.

3. Ahmed, S.I.; Hayat, M.Q.; Tahir, M.; Mansoor, Q.; Ismail, M.K.; Bates, R.B. Pharmacologically active flavonoids from the anticancer, antioxidant and antimicrobial extracts of Cassia angustifolia Vahl. BMC Complem. Altern. Med. 2016, 16, 460. [CrossRef] [PubMed]

4. Sundaramoorthy, S.; Gunasekaran, S.; Arunachalam, S.; Sathiavelu, M. A phytopharmacological review on Cassia species. J. Pharm. Sci. Res. 2016, 8, 260.

5. Sbrana, C.; Avio, L.; Giovannetti, M. Beneficial mycorrhizal symbionts affecting the production of health-promoting phytochemicals. Electrophoresis 2014, 35, 1535-1546. [CrossRef]

6. Singh, A.K.; Singh, A.; Singh, S. Impact of sowing and harvest times and irrigation regimes on the sennoside content of Cassia angustifolia Vahl. Ind. Crops Prod. 2018, 125, 482-490.

7. Cardoso, I.M.; Kuyper, T.W. Mycorrhizas and tropical soil fertility. AGR Ecosyst Environ. 2006, 116, 72-84. [CrossRef]

8. Parniske, M. Arbuscular mycorrhiza: The mother of plant root endosymbioses. Nat. Rev. Microbiol. 2008, 6, 763-775. [CrossRef]

9. Harley, J.L.; Harley, E.L. A check-list of mycorrhiza in the British flora. New Phytol. 1987, 105, 1-102. [CrossRef]

10. Huang, Z.; Zou, Z.; He, C.; He, Z.; Zhang, Z.; Li, J. Physiological and photosynthetic responses of melon (Cucumis melo L.) seedlings to three Glomus species under water deficit. Plant Soil 2011, 339, 391-399. [CrossRef]

11. Sampathkumar, G.N.; Prabakaran, M.; Rajendra, R. Association of AM-fungi in some medicinal plants and its influence on growth. In Organic Farming and Mycorrhizae in Agriculture; IK Int. Pub. House Pvt. Ltd.: New Delhi, India, 2007; pp. 101-106.

12. Pistelli, L.; Ulivieri, V.; Giovanelli, S.; Avio, L.; Giovannetti, M.; Pistelli, L. Arbuscular mycorrhizal fungi alter the content and composition of secondary metabolites in Bituminaria bituminosa L. Plant Biol. 2017, 19, 926-933. [CrossRef] [PubMed]

13. Selmar, D.; Kleinwachter, M. Influencing the product quality by deliberately applying drought stress during the cultivation of medicinal plants. Ind Crops Prod. 2013, 42, 558-566. [CrossRef]

14. Chang, W.; Sui, X.; Fan, X.X.; Jia, T.T.; Song, F.Q. Arbuscular mycorrhizal symbiosis modulates antioxidant response and ion distribution in salt-stressed Elaeagnus angustifolia seedlings. Front. Microbiol. 2018, 9, 652. [CrossRef] [PubMed]

15. Mittler, R. Oxidative stress, antioxidants and stress tolerance. Trends Plant Sci. 2002, 7, 405-410. [CrossRef]

16. Evelin, H.; Kapoor, R. Arbuscular mycorrhizal symbiosis modulates antioxidant response in salt-stressed Trigonella foenum-graecum plants. Mycorrhiza 2014, 24, 197-208. [CrossRef]

17. Demidchik, V. Mechanisms of oxidative stress in plants: From classical chemistry to cell biology. Environ. Exp. Bot. 2015, 109, 212-228. [CrossRef] 
18. Ghorbanli, M.; Ebrahimzadeh, H.; Sharifi, M. Effects of $\mathrm{NaCl}$ and mycorrhizal fungi on antioxidative enzymes in soybean. Biol. Plant. 2004, 48,575-581. [CrossRef]

19. He, Z.; He, C.; Zhang, Z.; Zou, Z.; Wang, H. Changes of antioxidative enzymes and cell membrane osmosis in tomato colonized by arbuscular mycorrhizae under $\mathrm{NaCl}$ stress. Colloids Surf. B Biointerfaces 2007, 59, 128-133. [CrossRef]

20. Garg, N.; Manchanda, G. Role of arbuscular mycorrhizae in the alleviation of ionic, osmotic and oxidative stresses induced by salinity in Cajanus cajan (L.) Millsp.(pigeonpea). J. Agron. Crop Sci. 2009, 195, 110-123. [CrossRef]

21. Hajiboland, R.; Aliasgharzadeh, N.; Laiegh, S.F.; Poschenrieder, C. Colonization with arbuscular mycorrhizal fungi improves salinity tolerance of tomato (Solanum lycopersicum L.) plants. Plant Soil 2010, 331, 313-327. [CrossRef]

22. Estrada, B.; Aroca, R.; Barea, J.M.; Ruiz-Lozano, J.M. Native arbuscular mycorrhizal fungi isolated from a saline habitat improved maize antioxidant systems and plant tolerance to salinity. Plant Sci. 2013, 201, 42-51. [CrossRef] [PubMed]

23. Gerdemann, J.W.; Nicolson, T.H. Spores of mycorrhizal Endogone species extracted from soil by wet sieving and decanting. Trans. Brit. 1963, 46, 235-244. [CrossRef]

24. INVAM. International Culture Collection of (Vesicular) Arbuscular Mycorrhizal Fungi. 2013. Available online: http://invam.wvu.edu (accessed on 5 October 2013).

25. Phillips, J.M.; Hayman, D.S. Improved procedures for clearing roots and staining parasitic and vesicular-arbuscular mycorrhizal fungi for rapid assessment of infection. Trans. Brit. 1970, 55, 158-160. [CrossRef]

26. Alqahtani, A.; Noman, O.M.; Rehman, M.T.; Siddiqui, N.A.; Alajmi, M.F.; Nasr, F.A.; Shahat, A.A.; Alam, P. The influence of variations of furanosesquiterpenoids content of commercial samples of myrrh on their biological properties. Saudi Pharm. J. 2019, 27, 981-989. [CrossRef] [PubMed]

27. Li, W.; Hosseinian, F.S.; Tsopmo, A.; Friel, J.K.; Beta, T. Evaluation of antioxidant capacity and aroma quality of breast milk. Nutrition 2009, 25, 105-114. [CrossRef] [PubMed]

28. Li, X.; Wang, X.; Chen, D.; Chen, S. Antioxidant activity and mechanism of protocatechuic acid in vitro. Funct. Food Health Dis. 2011, 1, 232-244. [CrossRef]

29. Mann, C.; Markham, J. A new method for determining the minimum inhibitory concentration of essential oils. J. Appl. Microbiol. 1998, 84, 538-544. [CrossRef]

30. Sulaiman, G.M. Antimicrobial and cytotoxic activities of methanol extract of Alhagi maurorum. Afr. J. Microbiol. Res. 2013, 7, 1548-1557.

31. Mandal, S.; Upadhyay, S.; Wajid, S.; Ram, M.; Jain, D.C.; Singh, V.P.; Abdin, M.Z.; Kapoor, R. Arbuscular mycorrhiza increase artemisinin accumulation in Artemisia annua by higher expression of key biosynthesis genes via enhanced jasmonic acid levels. Mycorrhiza 2015, 25, 345-357. [CrossRef]

32. Tejavathi, D.H.; Anitha, P.; Murthy, S.M.; Nijagunaiah, R. Effect of AM fungal association with normal and micropropagated plants of Andrographis paniculata Nees on biomass, primary and secondary metabolites. Int. J. Plant Sci. 2011, 2, 338-348.

33. Copetta, A.; Lingua, G.; Berta, G. Effects of three AM fungi on growth, distribution of glandular hairs, and essential oil production in Ocimum basilicum L. var. Genovese. Mycorrhiza 2006, 16, 485-494. [CrossRef] [PubMed]

34. Toussaint, J.P.; Smith, F.A.; Smith, S.E. Arbuscular mycorrhizal fungi can induce the production of phytochemicals in sweet basil irrespective of phosphorus nutrition. Mycorrhiza 2007, 17, 291-297. [CrossRef] [PubMed]

35. Zubek, S.; Mielcarek, S.; Turnau, K. Hypericin and pseudohypericin concentrations of a valuable medicinal plant Hypericum perforatum L. are enhanced by arbuscular mycorrhizal fungi. Mycorrhiza 2012, 22, 149-156. [CrossRef] [PubMed]

36. Giovannetti, M.; Avio, L.; Barale, R.; Ceccarelli, N.; Cristofani, R.; Iezzi, A.; Mignolli, F.; Picciarelli, P.; Pinto, B.; Reali, D.; et al. Nutraceutical value and safety of tomato fruits produced by mycorrhizal plants. Br. J. Nutr. 2012, 107, 242-251. [CrossRef]

37. Chetri, S.K.; Kapoor, H.; Agrawal, V. Marked enhancement of sennoside bioactive compounds through precursor feeding in Cassia angustifolia Vahl and cloning of isochorismate synthase gene involved in its biosynthesis. PCTOC 2016, 124, 431-446. [CrossRef] 
38. Chen, S.; Jin, W.; Liu, A.; Zhang, S.; Liu, D.; Wang, F.H.C. Arbuscular mycorrhizal fungi (AMF) increase growth and secondary metabolism in cucumber subjected to low temperature stress. SCI HORTIC 2013, 160, 222-229. [CrossRef]

39. Hashem, A.; Alqarawi, A.A.; Radhakrishnan, R.; Al-Arjani, A.B.F.; Aldehaish, H.A.; Egamberdieva, D.; Abd Allah, E.F. Arbuscular mycorrhizal fungi regulate the oxidative system, hormones and ionic equilibrium to trigger salt stress tolerance in Cucumis sativus L. Saudi J. Biol. Sci. 2018, 25, 1102-1114. [CrossRef]

40. Elansary, H.O.; Szopa, A.; Kubica, P.; Ekiert, H.; Ali, H.M.; Elshikh, M.S.; Abdel-Salam, E.M.; El-Esawi, M.; El-Ansary, D.O. Bioactivities of traditional medicinal plants in Alexandria. Evid. Based Complementary Altern. Med. 2018, 2018, 1463579. [CrossRef]

41. Chatterjeesup, S.; Dutta, S. A survey on VAM association in three different species of Cassia and determination of antimicrobial property of these phytoextracts. J. Med. Plant Res. 2010, 4, 286-292.

42. Demirezer, L.O.; Karahan, N.; Ucakturk, E.; Kuruuzum-Uz, A.; Guvenalp, Z.; Kazaz, C. Fingerprinting of sennosides in laxative drugs with isolation of standard substances from some Senna leaves. Rec. Nat. Prod. 2011, 5, 261-270.

43. Morris, J.B.; Wang, M.L.; Tonnis, B.D. Variability for Sennoside A and B concentrations in eight Senna species. Ind Crops Prod. 2019, 139, 111489. [CrossRef]

44. Dhanani, T.; Singh, R.; Reddy, N.; Trivedi, A.; Kumar, S. Comparison on extraction yield of sennoside A and sennoside B from senna (Cassia angustifolia) using conventional and non-conventional extraction techniques and their quantification using a validated HPLC-PDA detection method. Nat. Prod. Res. 2017, 31, 1097-1101. [CrossRef] [PubMed]

Publisher's Note: MDPI stays neutral with regard to jurisdictional claims in published maps and institutional affiliations. 